\title{
The Study of Application of High Water Material in Filling Mining Technology
}

\author{
Zhongming ZHAO \\ School of Energy Science and Engineering, \\ Henan Polytechnic University, \\ Jiaozuo 454003, China \\ liuyl3608@126.com \\ Yongliang LIU \\ School of Energy Science and Engineering, \\ Henan Polytechnic University, \\ Jiaozuo 454003, China \\ liuyl3606@126.com
}

\author{
Yi Li \\ School of Computer Science and Technology, \\ Henan Polytechnic University, \\ Jiaozuo 454003, China \\ lyirene13@gmail.com
}

\begin{abstract}
This paper introduced the advantages about the application of high water material in the filling mining under the combination of its actual situation of coal mine. These advantages included the fluidity, expansibility, strength of backfilling, initial investment of high water material and so on. The research results showed that high water material could control the surface subsidence effectively and liberate the coal resources under water, railway and building in a great extent. The success application of the high water material has certain social benefits and economic benefits, and even embodied the concept of "Green mining", meanwhile in response to strong call of harmonious mining ecological. The governers worked in the mine at all levels should spare no efforts to afflicate the application of high water material in the filling ming technology. As the coal resource decrease obviously, we should take some measures and methods to increase the rate of recovery.
\end{abstract}

Keywords-Filling mine; Surface subsidence; Liberation pressure coal; Green mining; Seam structure.

\section{INTRODUCTION}

Based on development of China in the special period, economic development mainly relies on the traditional energy industry. Although the traditional energy industry could bring the economic development for us, at the same time the natural environment has suffered from the damage in different degrees, especially the mining area ecological environment damage [1-3]. The surface subsidence, coal gangue accumulation and surface water pollution are all the problems currently in the process of coal production which are urged to be solved. In order to solve these problems which damage the surrounding environment, Chinese academician Qian Ming-gao proposed the green mining technology of coal resources. In the "Green mining" technology system, filling mining is an important part of it, and the key of the technology is filling materials [4-7]. High water swelling material has some expected characters such as strong liquidity, better expansibility and the early strength. In addition, high water swelling material could be transported easily and realize the reach caving top actively. In view of high water material is successfully applied in coal mine, the authors suggested that the filling mining technology with high water material can promote the sustainable development of China's coal mine in a certain extent.

The surface subsidence is caused by underground coal mining, and the surface subsidence is the results of cover rock moving from lower to upper gradually which transferred to the surface. In order to control ecological environmental disasters caused by coal mining ground subsidence, a series of methods have been applied to the practical project, such as water filling, cemented filling, paste filling, high water widespread application in metal mines and so on, They are all based on meet the practical engineering needs and played a key role to prevent underground burst disaster. Also, in order to reduce the mining cost, super high water filling material is a new technology which been went on to test in production ${ }^{[12-14]}$, and for large-scale mining with filling. The results showed that the use of super high water material not only reduced the mining cost, but also meet the requirements of the protection of the surface buildings. The development course of Chinese various filling technology roughly is shown in Figure 1.

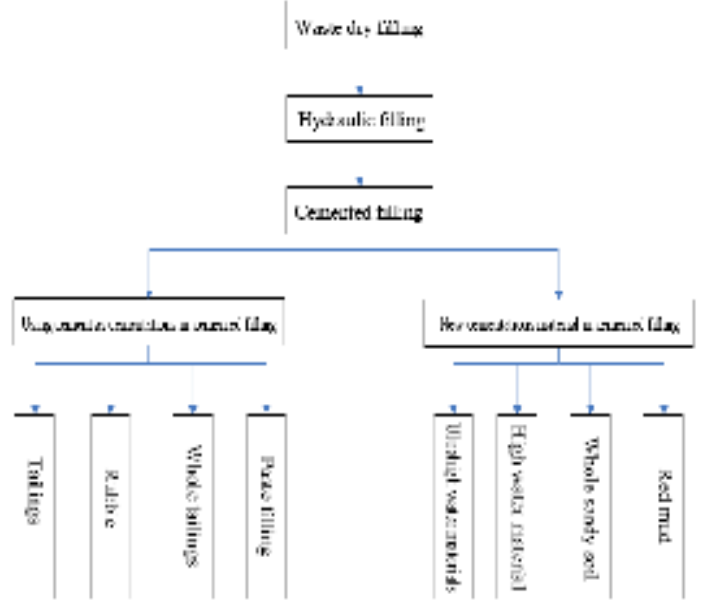

Figure 1. Development of backfill technology 


\section{THE REGIONAL GEOLOGICAL CONDITIONS OF FILLING TEST}

The actual filling mining working face is composed of 2 sections in a mine, one of which is $70 \mathrm{~m}$ in the direction of trend; the other is $75 \mathrm{~m}$ in the direction of inclination. The practical two working face advancing distance accumulated $145 \mathrm{~m}$. Working face in coal mine working face has the advantages of simple structure, no fold zone, subsided column, igneous rock geological structure. The geological conditions of mining area are relatively simple, only found the existence of water in the local section of the roof, and the rest of the filling area is suitable. Normal mine expected water inflow in the filling working face was $10 \mathrm{~m} 3 / \mathrm{h}$, then the maximum water inflow was $25 \mathrm{~m} 3 / \mathrm{h}$. Mine geological conditions and the water inflow described by the above, they had no effect on the implementation of backfill mining. So this experimental filling coal mining working face had typical characteristics. And the mine belonged to a low gas mine, so the filling mining with high water material was conducted more smoothly.

\section{HIGH WATER MATERIAL}

\section{A. Interpolation function}

The filling material is composed of 2 parts. The socalled high water refers to water volume content accounted for more than $95 \%$ of the total volume, and the $95 \%$ water volume is called common material ${ }^{[15-17]}$. Material consists of main material (A material, B material), subsidiary material (AA material, $\mathrm{BB}$ material). The main components of A material are sulphoaluminate cement. AA material consists of compound retarding dispersant. B material is composed of lime and gypsum. BB material is composed of composite accelerator. A、AA、B、BB material are shown in Figure 2. $\sim$ Figure 5.

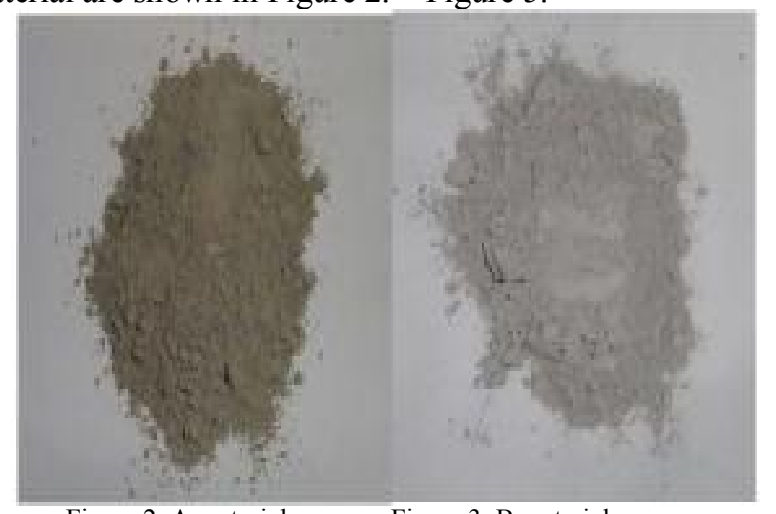

Figure 2. A material Figure 3. B material

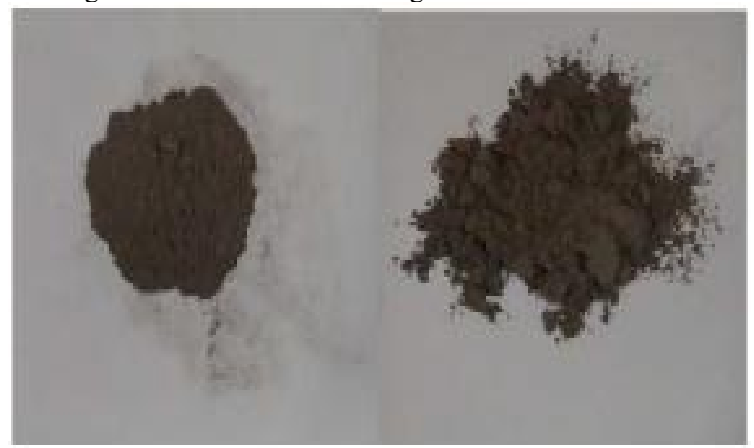

Figure 4. AA material

Figure 5. BB material
After mixing the above materials together, material filling body is formated, and its moisture content can reach about $90 \%$, which is called the high water swelling material, which is shown in Figure 6. The characteristics of the filling material as follows:

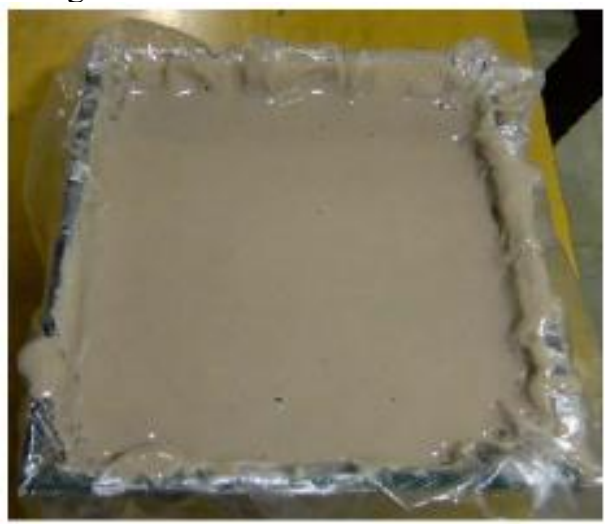

Figure 6. A and B single slurry mixed

(1) The strong fluidity. The filling materials keep good mobility as liquid within 2 hours, which is convenient for transportation by pipeline.

(2) The moderate expansibility. The filling slurry begins to solidification and expansibility after 2 hours. In the mined-out area, the filling body can contact the roof initiatively.

(3) The great strength of filling body. The filling body which is made of the mixed filling slurry begin to withstand the pressure after 8 hours; the uniaxial compressive strength of filling body reinforced over time; after 28 days minimum uniaxial compressive strength can reach $2.2 \mathrm{Mpa}$; after 1 month the filling strength can reach more than $10 \mathrm{Mpa}$, which can support the caving strata.

(4) The extensive material source and low cost. The main ingredient is basically the mine waste, thus we can make full use of the waste products and can reduce the pollution of the environment. Accessories are obtained easily and the price is low.

(5) The sufficient stability. The main filling compounds are so stable that can control the roof strata movement effectively in the long run.

Filling system mainly includes: slurry configuration system, slurry mixing system, slurry delivery system. The filling system has many advantages such as controllable, large conveying capacity, long conveying distance and occupying less equipment etc.

\section{B. The Effect of Filling}

In the progress of filling mine engineering, advance support pressure, roof and floor shift near in filling area and surface subsidence above the working face were observed.

(1) Advance support pressure.

Make the following contrast as to the high water material applied in the filling working face. The biggest peak pressure in front of the coal wall is $0.52 \mathrm{MPa}$, no advance stress concentration phenomenon and periodic pressure is not obvious as well; however, in the caving working face, the peak value of maximum pressure is $2.87 \mathrm{MPa}$ and periodic pressure is very obvious. The contrast results show high water filling material can effectively alleviate the pressure behavior the working face. 
Comparison curves of the two mine methods is shown in Figure 7.

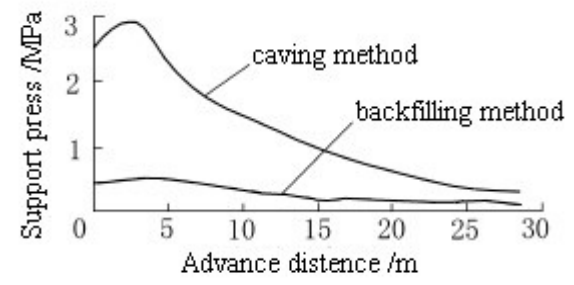

Figure 7. The comparison curves of the two mine methods

(2) Roof and floor shift near in filling area.

The top and bottom of closer observation point is arranged on the working face of filling area. The collected data show that: compared with the full caving method, in the filling mine working face, roof and floor closer value range between only $0.5 \mathrm{~mm} 20 \mathrm{~mm}$. mean shift near amount is $6.06 \mathrm{~mm}$. This contrast fully shows that the high water used in filling working face workface could control the roof caving, even without roof and floor obvious closer. In addition, observation points is set in the surface and its collecting data also proved that filling mine method can control surface subsidence and the data also show that the surface subsidence values is between the range of $2 \mathrm{~mm}$ $5 \mathrm{~mm}$, and after filling mine surface subsidence control effect is obvious.

(3) Roof and floor shift near in filling area.

The top and bottom of closer observation point is arranged on the working face of filling area. The collected data show that: compared with the full caving method, in the filling mine working face, roof and floor closer value range between only $0.5 \mathrm{~mm} 20 \mathrm{~mm}$. mean shift near amount is $6.06 \mathrm{~mm}$. This contrast fully shows that the high water used in filling working face workface could control the roof caving, even without roof and floor obvious closer. In addition, observation points is set in the surface and its collecting data also proved that filling mine method can control surface subsidence and the data also show that the surface subsidence values is between the range of $2 \mathrm{~mm}$ $5 \mathrm{~mm}$, and after filling mine surface subsidence control effect is obvious.

\section{Requirements of Ground Control}

The filling material is the core of filled goaf technology, wherein the backfill material performance determines the filling effect and affects the high or low cost of filling, which plays a key role in subsidence-reducing effect of the final surface ${ }^{[18]}$. To this end, the mineral composition testing, the paste liquidity test, the specimen strength test and theoretical analysis are taken to study the performance and proportion of gangue-fly ash ingredients of the filling material. It has resulted in some innovations. According to the process of goaf-filling and the rock deformation theory in goaf areas, the basic performance of the filling material is analyzed. The early strength of the backfill should be above $0.15 \mathrm{MPa}$ to meet their stable self-sustaining. The late strength of the backfill should match its load in goaf area. Bleeding rate should be controlled between $1.5 \%$ $4.5 \%$. in order to ensure that the filling material is capable of bleeding, without any excess. In order to achieve pumping demand, the slump of the filling material should be more than $20 \mathrm{~cm}$. And the coal gangue of coarse aggregate should be met a certain graduation requirements.

\section{DEVELOPMENT PROSPECT}

Coal acts as the major primary energy in our country, so it has the vital significance on whether our country can have a long-term stable development. However, in recent years, with the increasing demands of mining resources and strengthening exploitation, the reductions of resources reserves were inevitable. Therefore, it is particularly important that improving the coal mining rate in the greatest degree and reducing the destruction of natural environment. The filling technology with high water material can make the good social benefit and economic benefit. Specific performances will be illustrated in the following four aspects:

(1) Coal mining work underground environment has got optimized and the safety degree of coal mining has also got improved. The filling body set in the mine-out area can effectively control the movement of surrounding rock, which can reduce the disaster of water inrush from the floor and caving accident of roof. In addition, the goaf get the support of filling body, then toxic and harmful gas in the surrounding goaf has been effectively closed, which can reduce the contact chances of the harmful gas and fresh air. So it is very favorable for the prevention of mine gas outburst disasters.

(2) The filling technology can reduce the surface subsidence and keep the maintenance of the ecological environment in the whole mining area. Because of the existence of the filling body in mined-out area, the roof and floor shift near amount in the mine working face decreased obviously. Caving zone, fractured zone and bending zone will basically not occur instead of conventional roof management method, so that you can reduce the damage of the entire ecological environment in mining areas to the greatest extent.

(3) The liberation of pressure coal can improve the mining rate. The essence of filling mine technology is take advantage of filling body instead of the conventional protection coal pillar. In the condition of mine safety, carrying out filling mine can get as much coal source as possible mining and deal with the problem about pressure coal.

(4) Industrial wastes are reused in a good degree in order to construct a virtuous economy circle of coal enterprise. The most important industrial wastes of coal mine include: fly ash and coal gangue. And the reuse of them has a very positive meaning as to mine enterprise. The filling mine technology with high water material will not only put coal mine waste into reuse, but also meet the development requirements of the circular economy.

\section{CONCLUSIONS}

Taking use of high water material into carry out filling mine not only can reduce the surrounding environmental damage in the progress of coal mining, but also improve the utilization rate of a large number of industrial wastes. Both of them can promote the development of circular economy in coal mine. High water material applied in filling mine technology can liberate the pressure coal effectively and improve the recovery of coal resources. It helps mine search a new economic growth point. At the same time, this filling technology is also the future trend of coal enterprises which can help them achieve green development. So authors believe that the filing technology 
whit high water material can be well applied in coal mine widely in the future, meanwhile embody the advance and science of this new technology.

\section{ACKNOWLEDGMENT}

The research work was supported by Natural Science Foundation of Henan Provincial under Grant No. 0411052700 and Science and Technology Research Project of Henan Provincial under Grant No. 0324210048.

\section{REFERENCES}

[1] QIAN Ming-gao, XU Jia-lin, MIAO Xie-xing. Green technique in coal mining[J]. Journal of China University of Mining \& Technology, 2003, 32(4): 343-348.(In Chinese)

[2] MIAO Xie-xing, QIAN Ming-gao. Research on green mining of coal resources in China: current status and future prospects[J]. Journal of Mining \& Safety Engineering, 2009. 26(1): 1-14.(In Chinese)

[3] YAN Shao-hong, ZHANG Hua-xing. Status of filling mining technology in coal mines of China[J]. Coal Mining Technology, 2008. 13(3): 1-3.(In Chinese)

[4] LIU Tong-you. Filling mining technology and its application[M]. Beijing: Metallurgical Industry Press, 2001: 357-391.(In Chinese)

[5] FENG Guang-ming, WANG Cheng-zhen. Process system of goaf filling with ultra-high-water materials and application[J]. Journal of Shandong University of Science and Technology, 2011, 30(2): 1-8.(In Chinese).

[6] FENG Guang-ming, WANG Cheng-zhen, LI Feng-kai, et al. Research on open back-filling with highly-water-absorbing material[J]. Journal of Mining and Safety Engineering, 2010, 27(4): 453-457.(In Chinese)

[7] WU Long-fel, ZHOU Hua-qiang, LI Feng, et a1. Discuss on influencing factors of surface subsidence caused by backfilling
mining[J]. Energy Technology and Management, 2008(1): 2123.(In Chinese)

[8] LI Feng-kai, FENG Guang-ming, JIA Kai-jun, et al. Research on ultra-high-water material backfill method in Taoyi coal mine[J]. Journal of Coal Mine Engineering, 2011,11(1):63-66.(In Chinese).

[9] SUN Chun-dong. Study on overlying strata movement behavior for long wall filling mining of super high-water material and its control [D]. Xuzhou: China University of Mining and Technology, 2012.(In Chinese).

[10] FENG Guang-ming. Research on the super high-water packing material and filling mining technology and their application[D]. Xuzhou: China University of Mining and Technology, 2009.(In Chinese)

[11] Fall,M.et al. Experimental characterization of the influence of tailings fineness and densityon the quality of cemented paste back fill[J].Minerals Engineering,2005, 18:41-44.

[12] Amaratunga,L.M. old-Bond Agglomeration of Reactive Pyrrhotite Tailings for Backfill Using Low Cost Bingers: ypsum Hemihydrate and Cement[J].Minerals Engineering,1995,8(12):1455-1465.

[13] Kesimal,A.et al .Evaluation of paste backfill mixtures consisting of sulphide-rich mill tailings and varying cement contents[J].Cement and Concrete Research,2004,34:1817-1822.

[14] Ercikdi,B.et al. Cemented paste backfill of sulphide-rich tailings:Importance of binder type and dosage[J]. Cement\&Concrete Composites, 2009, 31:268-274.

[15] Kesimal,A.et al. Effect of properties of tailings and binder on the short-and long-term strength and stability of cemented paste backfill[J]. Materials Letters, 2005, 59:3703-3709.

[16] Huynh,L.et al. Effect of polyphosphate and naphthalene sulfonate formaldehyde condensate on the rheological properties of dewatered tailings and cemented paste backfill[J]. Minerals Engineering 2006, 19:28-36.

[17] Benzaazoua,M. et al. Chemical factors that influence the performance of mine sulphidic paste backfill[J].Cement and Concrete Research,2002,32:1133-1144.

[18] Fall,M. Influence of curing temperature on strength, deformation behaviour and pore structure of cemented paste backfill at early ages[J].Construction and Building Materials, 2006. 